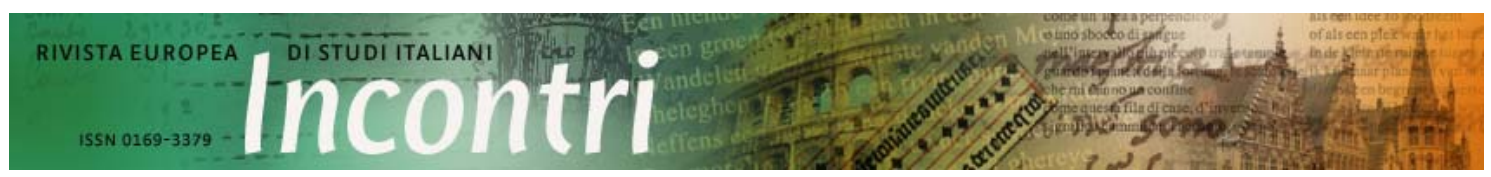

Anno 34, 2019 / Fascicolo 1 / p. 157-162 - www. rivista-incontri.nl - http:// doi.org/ 10.18352/ incontri. 10300 (c) The author(s) - Content is licensed under a Creative Commons Attribution 3.0 Unported License Publisher: Werkgroep Italië Studies, supported by Utrecht University Library Open Access J ournals

\title{
SEGNALAZIONI - SignALEMENTEN - NOTES
}

\section{J uryrapport voor de Onderzoeksprijs Werkgroep Italië Studies 2017}

De onderzoeksprijs van de Werkgroep Italië Studies 2017 bekroont een wetenschappelijke, archeologische of kunsthistorische studie met betrekking tot Italië die in 2015, 2016 of 2017 is verschenen. Zowel monografieën, verzamelbundels als artikelen komen in aanmerking. Niet gepubliceerde dissertaties kunnen niet worden bekroond. Meer informatie betreffende het reglement en potentiële laureaten is te vinden op: http:// www. italiestudies. nl/ prij zen/ onderzoeksprijs.

De jury voor de onderzoeksprijs 2017 was als volgt samengesteld: Maria Forcellino (voorzitter van de WIS), Jan de J ong (Rijksuniversiteit Groningen) \& Hans Cools (KU Leuven).

Deze prijs bestrijkt een bijzonder breed domein. Zowel archeologen als kunstwetenschappers dingen er, als leefden wij nog in de tijd van Johann Winckelmann, naar mee. Die brede opzet vergemakkelijkte de taak van de jury niet. Bovendien heeft zij zich niet beperkt tot het beoordelen van de ingekomen stukken. Om een zo breed als mogelijk beeld van de betrokken disciplines in de Lage Landen te krijgen, is zij tevens actief op zoek gegaan naar aansprekende studies in de betrokken vakgebieden.

Van oudsher fungeren de drie Nederlandse en Belgische instituten in Italië als even zovele brandpunten voor archeologisch en kunstwetenschappelijk onderzoek. In Rome en Leiden leidden J eremia Pelgrom en Tesse Stek een aansprekend project over de Romeinse kolonisatie van Centraal-Italië ten tijde van de late Republiek. Daarbij speurden zij middels survey-archeologie naar sporen in het landschap van die kolonisatie. Eén van de voornaamste uitkomsten van dit project is dat de Romeinse aanwezigheid in die kolonies sterker blijkt te zijn geweest dan eerder gedacht. Op 18 september jongstleden promoveerde in Leiden één van de uitvoerders van dit project, Anita Casarotto op Spatial patterns in landscape archeology. Voorafgaand aan die promotie stelde Anita Casarotto enkele van haar onderzoeksresultaten reeds voor in een reeks fraaie artikelen. Een KNIR-stipendium stelt haar nu in de gelegenheid haar proefschrift om te werken tot een handelseditie. De jury wil Anita Casarotto dan ook vooral aanmoedigen weerom naar een volgende editie van de prijs mee te dingen.

Eerdere juryrapporten van de WIS stipten reeds aan dat de Nederlandse oudheidkunde zich onderscheidt door haar grote aandacht voor receptiegeschiedenis. Zo verscheen in 2015 de magistrale studie van Eric Moormann Pompei's Ashes. Daarin gaat de Nijmeegse hoogleraar op zoek naar de sporen die de beroemde uitbarsting van de Vesuvius sinds de start van de opgravingen in Pompei in het midden van de achttiende eeuw in de Europese cultuur heeft nagelaten. Nog in 2015 rolde Mietjes, monsters en barbaren van de Leuvense classicus Toon Van Houdt van de persen. Het boek won de Homerusprij s van het Nederlands Klassiek Verbond. Een jaar later volgden J an Bloemendals Latijn, cultuurgeschiedenis van een wereldtaal en David Reij sers opus magnum Een telkens nieuwe oudheid. De jury heeft deze stuk voor stuk indrukwekkende publicaties in overweging genomen, maar meende dat het hier veeleer om historische dan om archeologische publicaties ging. 
Zeer gecharmeerd was de jury ook van het bij Yale University Press gepubliceerde Rediscovering Architecture. Paestum in the eighteenth century, een monografie van de Leidse architectuurhistorica Sigrid de J ong. Daarin beschrijft zij aan de hand van nauwgezet bronnenonderzoek minutieus hoe de opgraving van die drie beroemde archaïsche Dorische tempels ons beeld van de Griekse kolonisatie van ZuidItalië, maar vooral ook van de klassieke architectuur voorgoed heeft veranderd. J ammer genoeg verscheen het boek van Sigrid de J ong volgens de officiële imprint reeds in 2014, al was het pas in het voorjaar van 2015 beschikbaar. Bijgevolg kon de jury, hoe graag zij dat ook had gewild, dit boek afgaand op het prijsreglement niet in overweging nemen.

Ook de beoefening van de academische kunstgeschiedenis in de Lage Landen bloeit. Maar de aandacht die daarbij in Nederland en Vlaanderen aan Italië wordt besteed, neemt af, zo constateert de jury enigszins zorgelijk. Wel zijn nog enkele mooie publicaties op komst. In 2015 en 2017 verdedigden respectievelijk Elisa Goudriaan en Klazina Botke, die beiden werden gevormd door de Groninger emeritus Henk van Veen, belangwekkende proefschriften over de wijze waarop Florentijnse patriciërs uit de zestiende en de zeventiende eeuw in hun kunstmecenaat omgingen met de greep naar de macht van de Medici. Van die eerste dissertatie verscheen dit jaar al een handelseditie bij Brill. De jury hoopt dan ook dat Elisa Goudriaan zal meedingen naar de volgende editie van de prijs. Zij wil tevens Klazina Botke aanmoedigen op haar beurt het manuscript van haar proefschrift tot een boek om te werken.

Verder heeft de jury met veel belangstelling kennis genomen van J oost Keizers eind 2017 bij de prestigieuze Britse uitgeverij Routledge verschenen monografie The Realism of Piero della Francesca. De jury heeft bewondering voor het theoretisch vernuft van J oost Keizer, maar zij meent tevens dat de auteur zich op deze manier vrijwel geheel loszingt van de objecten, waar het naar haar oordeel in de kunstwetenschap uiteindelijk om te doen is.

Van een geheel andere orde is de door Bram de Klerck geredigeerde en ook goeddeels door hem geschreven catalogus In het hart van de Renaissance. Schilderkunst uit Noord-Italië, 1500-1600. Die catalogus hoort bij een tentoonstelling die in het voorjaar van 2017 liep in het Rijksmuseum Twenthe en die eerder te zien was geweest in Warschau en Helsinki. Kern van deze reizende tentoonstelling waren drieëndertig schilderijen uit de destijds voor renovatie gesloten Pinacoteca Tosio Martinengo in Brescia. De afbeeldingen in de catalogus zijn prachtig, de essays zijn in een overtuigende volgorde geplaatst, logisch opgebouwd en waar nodig goed vertaald. Bram de Klerk schrijft buitengewoon prettig en helder. Deze publicatie is in de beste betekenis van het woord een publieksboek, die velen een introductie zal hebben geboden in de Noord-Italiaanse schilderkunst van de renaissance.

Veel specialistischer van opzet is de catalogus van de beroemde Berensoncollectie in de Florentijnse villa I Tatti die Machtelt Brüggen-Israëls in 2015 samen met Carl Brandon Strehlke het licht liet zien. De notities van veel voor het eerst grondig beschreven schilderijen zijn toonbeelden van onovertroffen acribie en de reproducties zijn stuk voor stuk van hoge kwaliteit. De catalogus bevat ook een knap essay van Machtelt Israëls over de Sienese schilderijen in de Berensoncollectie. Daarin bouwt zij verder op haar grote expertise op dit terrein en haalt zij onder andere de eerder verwaarloosde rol van Mary Berenson bij de sturing van haar echtgenoots aankoopgedrag voor het voetlicht.

Een derde en laatste catalogus die de jury onder ogen kwam, combineert de eerdergenoemde sterke kanten van zowel De Klerck als Brüggen-Israëls. Het gaat om De droom van keizer Constantijn. Kunstschatten uit de Eeuwige Stad. Dit boek hoort bij de tentoonstelling die in het najaar van 2015 en het voorjaar van 2016 liep in de 
Amsterdamse Nieuwe Kerk. Steunend op hun wereldwijd erkende expertise en op de contacten die zij in hun decennialange wetenschappelijke loopbanen hebben gelegd, slaagden beide curatoren erin kunstwerken die het Vaticaan en andere voorname Romeinse musea haast nooit verlaten, naar Nederland te halen. Deze bijna tachtig schatten koppelen zij in hun catalogus aan vijf korte, uiterst heldere essays. Daarin verhalen zij de jongste stand van de vaak door hen persoonlijk opgebouwde kennis over een reeks "moeilijke" onderwerpen aan het niet-specialistische publiek dat deze schitterende tentoonstelling in groten getale heeft bezocht. De droom van keizer Constantijn is dan ook een boek dat zich op het snijvlak van archeologie, kunstwetenschappen en oude geschiedenis bevindt en zeer velen in Nederland en daarbuiten op voortreffelijke wijze met deze disciplines laat kennis maken en hen introduceert in een van de belangwekkendste thema's van de Westerse cultuurgeschiedenis.

Bovendien brengt de Werkgroep Italië Studies op deze manier hulde aan twee van Nederlands meest vooraanstaande geesteswetenschappers. Beiden zetten zich al vele decennia lang in, eerst vanuit het Instituut in Rome en later vanuit Amsterdam en vooral Nijmegen, voor de bestudering en de verspreiding van de Italiaanse cultuur in de Lage Landen. Daarbij hebben zij onze kennis daarover aanzienlijk vergroot. Hun productie ligt hoog en is immer van grote kwaliteit; niet toevallig figureerde Eric Moormann al eerder in dit juryrapport. Wij zijn beide heren dus veel dank verschuldigd en daarom ook wil ik nu Eric Moormann naar voren uitnodigen om mede namens Sible de Blaauw de Onderzoeksprijs van de Werkgroep Italië Studies in ontvangst te nemen.

- Amsterdam, 5 oktober 2018

\section{Hans Cools}

KU Leuven

Blij de-Inkomststraat 21 - bus 3307

3000 Leuven (België)

hans.cools@kuleuven.be

\section{J an L. de J ong}

Rij ksuniversiteit Groningen

Oude Boteringestraat 34

9712 GK Groningen (Nederland)

J.L.de.J ong@rug.nl

\section{Maria Forcellino}

Universiteit Utrecht

Trans 10

3512 J K Utrecht (Nederland)

m.forcellino@uu.nl 


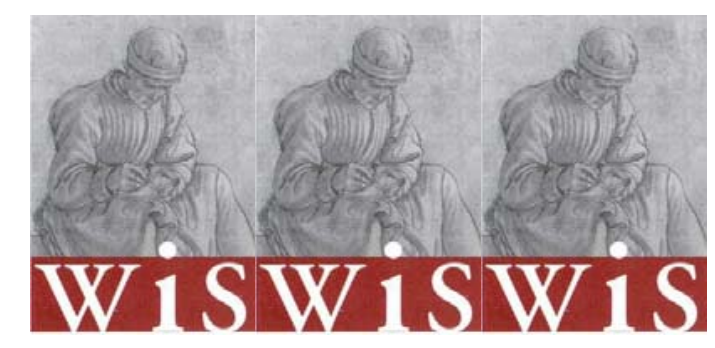

Verbale della giuria dello Scriptieprijs (Werkgroep Italië Studies 2017-2018)

II Werkgroep Italië Studies conta tra le sue attività quella di favorire gli studi nel campo dell'Italianistica: intesa qui nel suo significato più ampio di Studi umanistici che hanno come tema la cultura italiana. Assecondando questo proposito, ogni due anni viene assegnato lo Scriptieprijs che premia giovani studiosi che hanno concluso una laurea triennale (bachelor) o una laurea magistrale (master) con tesi pertinenti alla cultura italiana in una università dei Paesi Bassi e della Comunità Fiamminga del Belgio. L'edizione del 2017-2018 è stata bandita per premiare una ricerca difesa negli anni accademici 2016-2017 e 2017-2018 nell'ambito disciplinare della Storia dell'arte e dell'Archeologia.

II WIS ha istituito una commissione ad hoc composta dal dott. Gandolfo Cascio (presidente), il dott. Claudio Di Felice e la dott. ssa Maria Forcellino che ha valutato le diverse candidature e in sessione di consiglio unanimemente ha decretato i seguenti giudizi:

\section{Terzo classificato: J oery de Winter, MA}

Van de politisering van kunst naar de esthetisering van politiek. De doorwerking van het Italiaans futurisme in het fascisme van Benito Mussolini

Universiteit van Amsterdam

Relatore: dr. Gregor Langfeld

\section{Sinossi}

La ricerca segue le due traiettorie storiografiche seguite dal Fascismo e dal Futurismo, da cui scaturì un discorso frammentato tra questi due movimenti italiani. Ha il merito di aver evidenziato le differenze, tra l'altro analizzando i presunti contributi dei futuristi al Fascismo, contestualizzando e chiarendo le loro intenzioni durante il Ventennio. Ne risulta descritta la storia di un'alleanza destinata a fallire, in cui i futuristi hanno contribuito solo occasionalmente e marginalmente al successo del Fascismo, perché indirettamente e soltanto prima dello scoppio della Seconda Guerra mondiale, quando combatterono il governo liberale e la democrazia parlamentare, avallando così l'idea di una politica violenta. II candidato non manca di ricordare un dato storico noto: con I'uso dell'arte come propaganda di guerra, il Futurismo ha sostanzialmente contribuito a creare sostegno alla partecipazione dell'Italia alla guerra. In altre parole, il contributo maggiore dei futuristi all'ascesa del Fascismo è stato attraverso la politicizzazione dell' arte (visiva). Sebbene gli ideali futuristici quali I'attivismo, la tecnologia, la virilità, il culto della gioventù e dello sport, l' eroico ideale di avventura e la sacralizzazione della politica abbiano risuonato nel Fascismo maturo, il reale impatto del Futurismo sulla struttura del regime è stato di poco conto.

Le conclusioni a cui giunge la ricerca riportano che è stato giustamente riconosciuto da molto tempo il contributo del Futurismo alla promozione dell'arte moderna, ma sottolineano che il movimento ha anche abbracciato una politica che ha glorificato la guerra, ha contribuito alla scomparsa di un' Italia liberale, ha collaborato con il Fascismo e ha contribuito a costruire e sostenere la dittatura. 
Giudizio della Commissione

Questa ricerca affronta un tema classico, sebbene abbia il merito di non limitarsi all'analisi delle prime fasi del Futurismo, ma affronta anche l'intreccio degli artisti rappresentativi del movimento con il regime. La tesi presenta dunque le caratteristiche proprie di un buon lavoro scientifico; tuttavia, l'indagine presenta alcuni limiti: il più rilevante è che non riesce ad andare oltre la scarsa letteratura selezionata. A ciò si aggiunge che non sono impiegate fonti primarie in lingua italiana, ma solo nella loro traduzione in inglese. Infine, accanto ad un tradizionale ordine cronologico dei contenuti, il linguaggio tende a essere astratto e poco coinvolgente.

\section{Seconda classificata: Ida van Gelder, MA}

Un censimento dei prestiti dal nederlandese all'italiano. Per una storia etimologica di anmarren, bakboord, pompelmoes, bolwerc e schets Universiteit Leiden

Relatore: dr. Claudio Di Felice

Sinossi

La ricerca riguarda un settore della lessicografia ancora inesplorato: i prestiti di ambito nederlandese e fiammingo nella lingua italiana. II metodo è basato sullo spoglio elettronico del dizionario di Devoto-Oli e sullo spoglio manuale del Grande dizionario della lingua italiana di Salvatore Battaglia e sull'analisi dei lemmi raccolti da un punto di vista semantico e fono-morfologico. Si tratta di un totale di 361 prestiti, da cui sono stati estrapolati 5 lemmi, di cui si ripercorre la storia etimologica e il loro viaggio attraverso lingue ponte come il francese e il tedesco. Esse sono anmarren, da cui deriva amarrare, bakboord che ha dato babordo, pompelmoes/pompelmo, bolwerc/ baluardo, e schets/ sketch.

\section{Giudizio della Commissione}

La ricerca merita il secondo posto, considerata la quantità di lavoro svolta e la sua completa originalità. L'illustrazione del metodo è chiara ed estesa ben oltre i limiti richiesti solitamente per una tesi di laurea. L'interpretazione dei dati e la loro argomentazione critica sono convincenti, i risultati sono rilevanti, ma devono essere affinati e completati (manca difatti lo spoglio degli ultimi tre volumi del Battaglia).

Le domande di ricerca hanno ricevuto una risposta soddisfacente, ma devono essere portate a un livello di master per essere ampliate. I risultati sono comunque ragguardevoli, dato che il numero dei lemmi indicati nel Devoto-Oli sono stati più che triplicati e in molti casi retrodatati.

\section{Primo classificato: Nick Pouls, MA}

Last van stemmingswisselingen. De receptie van Claudius Ptolemaeus' Apuovía (Harmonieën) in de muziektheoretische ontwikkeling van de middentoonstemming in het laat vijftiende- en zestiende-eeuwse Italië

Radboud Universiteit Nijmegen

Relatore: prof. dr. Eric Moormann

\section{Sinossi}

Questa tesi di Master in Studi dell'antichità verte su un aspetto della storia della teoria musicale: il ruolo svolto dal trattato delle Armonie dell'astronomo Claudio Tolomeo sullo sviluppo teorico del tono medio alla fine del XV e nel XVI secolo in Italia. Le Armonie sono tornate sotto i riflettori nel Ventesimo secolo per via di un rinato 
interesse nei confronti della teoria musicale antica, con una conseguente polemica tra i classicisti, che reclamavano il rispetto delle fonti storiche, e i pionieri della prassi esecutiva e creativa. II tema è ancora di attualità: infatti idealmente questa tesi vuole collegarsi anche al dibattito scientifico sull'impiego di umori e temperamenti nella prassi esecutiva contemporanea.

La rilevanza di questa ricerca risiede in due diversi aspetti. Innanzitutto, intende diffondere la consapevolezza nei musicisti e negli ascoltatori di ogni genere di musica dello sviluppo storico degli stati d'animo, caratteristica fondamentale della composizione musicale. In secondo luogo, questa ricerca mette in luce le zone d'ombra della teoria musicale, in quanto soltanto i sostenitori della prassi esecutiva autentica sono consapevoli dei diversi stati d'animo impiegati nel XV e XVI secolo (si pensi al madrigale).

Lo studio offre:

1. una contestualizzazione storica delle Armonie tolomeiane anche in relazione alla loro ricezione nel Rinascimento

2. una ricostruzione dei rapporti con la matematica pitagorica

3. un quadro dell'influenza di Tolomeo sui primi teorici dell'umore dei mezzi toni e sulla separazione tra musica teorica e musica practica

4. un confronto con teorici del rinnovamento (Nicola Vicentino) e della continuità scolastica (Gioseffo Zarlino)

5. una direzione di studio verso posizioni teoriche diverse, come quella di Vincenzo Galilei, sostenitore della relazione tra espressione e musica

\section{Giudizio della Commissione}

Questa tesi è all'avanguardia della teoria musicale e della storia dell'accoglienza dell'antichità classica. L'argomento trattato dall'autore è specialistico, pertanto l'argomentazione non è sempre facile da seguire, ma è certamente logica nel suo sviluppo. Ciò che la commissione ha apprezzato è stata la possibilità di ripercorrere quella costante ricerca della perfezione matematica di altezze e intervalli da parte dei compositori del sedicesimo secolo.

Questa è una tesi molto originale, con una domanda ben formulata e un argomento convincente. Indubbie le capacità dell' autore, che ha studiato diverse fonti primarie e secondarie. Ma questo è precisamente il motivo per cui la ricerca può apparire elusiva agli occhi del lettore non specialista.

La commissione lamenta qualche trascuratezza formale, in particolare per quanto riguarda le citazioni non tradotte nella lingua del testo, I'olandese. Alquanto fuorviante la conclusione di per sé molto breve, ma essa si connota come un altro capitolo in cui si danno ulteriori informazioni sul dibattito quattro-cinquecentesco in cui la teoria tolomeiana fu protagonista.

La premiazione è avvenuta ad Amsterdam, nella sede dell'Istituto Italiano di Cultura per i Paesi Bassi il 4 ottobre 2018, alla presenza dei candidati e della commissione del WIS.

\section{Gandolfo Cascio}

Universiteit Utrecht

Trans 10, Kamer 0.61

3512 J K Utrecht (Olanda)

G.Cascio@uu.nl 